\title{
Viewpoint
}

\section{Global health education in the Dutch Caribbean: 50 years of a unique Groningen-Curaçao clinical clerkship program}

\author{
Ashley J Duits', Jan B Kuks², Jamiu O Busari ${ }^{3}$ \\ 1 Department of Medical Education, St. Elisabeth Hospital, Willemstad, Curaçao; Institute for Medical Education, University Medical Center Groningen, \\ Groningen, The Netherlands; Red Cross Blood Bank Foundation, Willemstad, Curaçao, ${ }^{2}$ Institute for Medical Education, University Medical Center \\ Groningen, Groningen, the Netherlands; Department of Neurology, University Medical Center Groningen, Groningen, The Netherlands, 3 Department \\ of Pediatrics, Zuyderland Hospital, Heerlen, The Netherlands; Department of Educational Development and Research, Faculty of Health, Medicine and \\ Life Sciences, University of Maastricht, Maastricht, The Netherlands
}

Keywords: sustainability, developing countries, medical education, global health

https://doi.org/10.29392/001c.13064

\section{Journal of Global Health Reports}

Vol. 4, 2020

\begin{abstract}
The globalization of healthcare has had a significant impact on healthcare delivery and human workforce development in many countries. Consequently, many educational institutions have had to revise the content of their medical curricula to focus on training and preparing future doctors to effectively cater to the needs of the "modern patient". The focus covers broader aspects of medicine that include environmental and professional culture and the impact of socioeconomic inequalities on the delivery of healthcare. Therefore, in most global health $(\mathrm{GH})$ education programs described, students undertake a specific part of their clinical rotation in a foreign (non-western) educational setting to facilitate authentic learning experiences within a resource-constrained environment. In this paper we present a unique Global Health program for medical interns between the University Medical Center Groningen, Netherlands and the Sint Elisabeth Hospital, Curaçao, Dutch Caribbean that has, for more than 50 years, been providing a one-year internship program as part of the formal Groningen curriculum. The program we describe, illustrates the essential requirements for best practice in GH education that fully complies with recently proposed GH program objectives and competencies. The characteristics of our long running program show the basic requirements necessary for sustainable and successful health education collaboration between institutions in high- and low/middle income countries. Finally, this program, which is part of a Dutch medical curriculum, not only provided unique global health learning experiences for the interns, but importantly also contributed to improving the general healthcare delivery services on the island of Curaçao as well.
\end{abstract}

In the last decade, the world has witnessed an exponential increase in the rate of population migration across continents, which has not only affected the global distribution of economic and infrastructural resources, but also the organization and consumption of health care services in many countries. In terms of the incidence and prevalence of illness conditions, several cases of imported, alien and exotic diseases from non-western countries into many western health care systems have been reported. ${ }^{1,2}$ The changes observed in the demographic profiles of the consumers and providers of care have also resulted in the need for different and novel approaches to the organization of health systems and the training of health care professionals. Hence, the current trend of globalization in health care has created a need for (future) doctors to be properly trained to effectively manage patients in a rapidly and ever-changing global ecosystem.

Recent and modern approaches to health professions education call for extensive and goal-oriented preparation of students so that they are capable and ready to take on the broader responsibilities of their profession and deal with the complexities of their duties as modern physicians. 3,4 Therefore within the context of a single and steadily growing global economy, the need to train physicians in global health care practices has ultimately arisen. The physician of today needs more than ever to possess specific behaviours, knowledge and skills to be able to effectively address the socioeconomic inequalities that exist between and within different communities (and countries). He or she needs to understand the impact of these inequalities on the access to healthcare, as well as on the organization and delivery of healthcare in general. Furthermore, this "understanding" extends beyond the physician's immediate and local health care setting alone, to include a broader, interconnected and global health care perspective.

According to the Belaggio Global Health Initiative, global health or global health practice $(\mathrm{GH})$ can be defined as "a field of healthcare rooted in the concepts of health equity, collaborative and multidisciplinary practice, patients and populations, and cross-cultural interactions". ${ }^{4}$ Recent literature on $\mathrm{GH}$ and the relevant competencies in this domain show that the socio-economic and environmental determi- 
nants of health as well as cultural diversity and health have not been adequately addressed in various medical curricula. In contrast, these competencies have been found to be highly relevant in the effective management of the emerging needs of the "modern" patient. ${ }^{4}$

In this paper, we describe the characteristics of a unique GH education program within a resource-limited environment in the Caribbean. This program, which has been running since 1967, is a collaborative effort between the University Medical Center Groningen (UMCG) in the Netherlands and the St. Elisabeth Hospital (SEHOS) in Curaçao, Dutch Caribbean. It can be considered as an example of a successful GH education program that has provided excellent training to medical students (and residents) and also fostered the improvement of healthcare quality within the local community. Interestingly this program has for the past 50 years complied with more recently introduced themes and objectives for GH education programs worldwide. 3,5,6

\section{GLOBAL HEALTH EDUCATION PROGRAM DESIGN}

In response to the need for $\mathrm{GH}$ education of physicians, several institutions have designed their medical curricula in a way that GH education is incorporated (and promoted) in their programs. For most of these programs, students from one institution or university (mostly in high income countries) undertake a specific part of their internship training (i.e. clinical rotation) in another institution or hospital in a foreign setting (preferably in a developing country/country with limited resources). ${ }^{7,8}$ The objectives of these GH programs include providing trainees with the opportunity to interact with patients and health care professionals within different health care settings. In this way, trainees are exposed to health care delivery processes in different and unfamiliar contexts and can interact with the various determinants of illness and disease that define the health care delivery process in those communities. These GH programs provide the trainees with the opportunity to be immersed in the context of the local health care system, facilitating authentic learning experiences and opportunities to appreciate the various challenges involved in health care choices that are made in resource-limited environments. ${ }^{9-11}$

\section{HISTORICAL OVERVIEW UMCG-SEHOS COLLABORATION}

In 1967 an internship program was developed for Dutch medical students by the UMCG together with the local general hospital SEHOS in Curaçao, Dutch Caribbean. With the start of this program half a century ago, SEHOS formally became an affiliated teaching hospital to UMCG in the Netherlands. The creation of the internship program in Curaçao was based on the premise that the medical learning environment on the island was attractive and strategic in exposing interns to global health issues. Embedding a Dutch medical curriculum in a Caribbean setting with its myriad of interesting medical challenges was therefore considered to be of great added value to the training of future Dutch physicians. From a Curaçao perspective the rationale for having the SEHOS become a teaching hospital was twofold. One was the potential benefit of the hospital's service to the community by running a well-structured medical training program relying on competent medical specialists, residents (in training), interns and qualified nurses and two, the added value of a medical teaching environment to the quality of patient care on the island resulting in opportunities to treat complex patient conditions locally and in collaboration with the UMCG. Examples of such clinical conditions include premature babies, patients with hematological and oncologic conditions as well as those with endstage renal disease requiring dialysis or kidney transplantation. To support this program an administrative vehicle was created, the Dutch Caribbean Foundation for Medical Education (NASKHO), which was tasked with the organization and coordination of the collaborative training program, continuous medical education of local medical professionals and supporting locally relevant scientific research. The importance of this program was recognized by the local government by fully financing all NASKHO activities.

Over the years, the hospital as an educational setting has expanded its collaboration with more tertiary medical institutions in the Netherlands in addition to providing accredited residency and pre-residency training for Dutch medical students of the UMCG. ${ }^{12}$ As an affiliate teaching hospital, SEHOS has created the necessary educational infrastructure for training medical students and residents, as well as recruiting a pool of (local) physicians and trained teachers for the UMCG internship program.

\section{UMCG EXTERNAL CLINICAL CLERKSHIP PROGRAM}

Over the past 50 years, the curriculum of the undergraduate medical training program at the UMCG has undergone several revisions. Despite the several iterations however, the curriculum has retained its one-year external clerkships (clinical rotations) for all of its interns. These external clerkships (or clinical rotations) of the UMCG are organized in conjunction with a selected group of affiliated teaching hospitals, including SEHOS. These affiliated hospitals include, next to SEHOS, Deventer Hospital, Isala Hospital Zwolle, Medical Center Leeuwarden, Medisch Spectrum Twente Enschede, Treant Zorggroep Emmen, Ziekenhuisgroep Twente Almelo (all in the Netherlands) and more recently Oldenburg Hospital in Germany. During the one-year external clinical rotation, the students get the opportunity to experience their roles as aspiring physicians in different cultural and educational environments, other than their university teaching hospital. Irrespective of location, all of the students follow the same curriculum within the teaching hospitals, fully complying with the official requirements of the Dutch medical education blueprint as set out in the revised Framework 2009. ${ }^{13}$ Each affiliate hospital receives subsidies to cover expenses for each UMCG student participating in the program.

Over the years, a constant challenge for the UMCG has been finding ways to create an educational infrastructure with the same format for training and evaluating its trainees in all of the affiliated teaching hospitals. Efforts 
made by the institution to ensure such an infrastructure, have included providing teacher-training programs to the teaching faculty in all of the affiliated teaching hospitals. Meanwhile, despite the apparent local challenges for an educational infrastructure, regular audits by the UMCG and Dutch authorities to assess the standard of the external clerkship in Curaçao have consistently demonstrated that quality of the program in SEHOS is comparable to the other UMCG affiliate teaching hospitals in the Netherlands, thereby fully complying with the official requirements for Dutch training programs.

Currently, the competency based training requirements for the clinical clerkship in the undergraduate medical program (G2010) encompasses ten to twelve 4 week rotations, covering the essential clinical specialties (including internal medicine, surgery, obstetrics and gynaecology, neurology, pediatrics), family medicine and social medicine/public health in the second Master year (M2). ${ }^{14}$ In the current G2010 medical education program SEHOS offers the full $2^{\text {nd }}$ Master year program of clinical clerkship (M2) catering to 25-30 students on a yearly basis. More than 1000 medical students have passed through the one-year clerkship program in SEHOS and graduated as medical doctors in the Netherlands over the past 50 years.

\section{SEHOS CLINICAL CLERKSHIP PROGRAM AND GLOBAL HEALTH EDUCATION PERSPECTIVES}

One of the interesting features of the SEHOS clinical clerkship is that the hospital is located in a non-western environment with limited health, economic, and manpower resources. ${ }^{12}$ Curaçao is a Dutch Caribbean island with an estimated population of 150.000 inhabitants. The island has SEHOS as its sole general and teaching hospital and is tasked with providing secondary and tertiary referral health services within the different clinical disciplines. ${ }^{12}$ Specialties served include adult, pediatric, and neonatal intensive care services. Socio-economic demographics of the island show that there is a relatively high aging population with a high prevalence of chronic diseases such as diabetes, obesity and hypertension. ${ }^{12}$ Most of the island and hospital's medical staff is local and trained in the Netherlands and the official language on the island is Dutch, which is used for all medical related correspondence and reports. The local language of Papiamento is spoken by everyone and a short training in this language is the only special requirement for UMCG students interested in this clinical clerkship.

The unique characteristic of the clinical rotation in the SEHOS is that students get the opportunity to experience learning within a different (non-western) educational context and culture. They are exposed to the basic principles of GH care, which fits into the framework of a curriculum they are familiar with. Due to the scale of the health care problems, local culture and infrastructure in Curaçao, the students also get the opportunity to engage in direct "handson" patient care encounters under direct supervision of residents and medical specialists (patient contacts). The environment of the island exposes the trainees to new and unfamiliar (non-western) pathologies while the local culture poses different medical problems/challenges to learn from, most of which are related to the different healthcare infrastructure and local patient health awareness (cultural difference). The trainees also get to work with patients from a different socio-economical background (i.e. middle income/low income country) that is distinct from the standard Dutch socio-economic environment (socio economical evaluation). Furthermore, because of the limited resources on the island, special attention is also paid to cost-effectiveness in patient management and reduction of unnecessary or superfluous diagnostic investigations. This emphasizes the importance of developing essential basic medical skills such as history taking and good physical examinations (basic environment). These features align well with current GH objectives and competencies as described by authoritative organizations like the UK Global Health Learning Outcomes Working Group and Consortium of Universities for Global Health (CUGH)(see Table 1).3,6 With respect to the organization of the in-hospital clinical rotations, the clerkships start with an introductory interview between the students and their designated department mentors. During this interview, each student is introduced to the organizational structure of the new health system they would be working in. The expected professional behaviours as well as, specific clinical, cultural, and operational aspects of the department (staff and patients) are also discussed. Patient communication in the local language is expected and encouraged.

For the rotations in family medicine, the student actively participates in the patient home visits with the general practitioner. During these visits (and when seeing patients at the general practitioner's office) the students experience a wide variety of clinical encounters. They obtain a broad impression of the local (healthcare) needs and of the social environment of the patients. At the end of the clerkship reflections of their impressions constitute a structural part of their evaluations by the general practitioner-mentor.

Finally, regarding the clinical rotations in public health, this is mainly introductory in nature. The students spend time in different departments (including epidemiology, ambulance service, infectious disease control and youth healthcare) understanding how healthcare is organized on the island and obtaining a clearer view of island specific (public) health issues that need attention.

As a structural part of the G2010 program a weekly student group and individual intervision session, guided by a professional coach, is scheduled. During these sessions topics like the global burden of disease, social determinants of health, medical ethics and professional practices are critically discussed based on the student's daily experience in their (unique) training environment while reflecting on their own values.

In a recently published paper, Eichenbaum proposed new GH competency domains ${ }^{15}$ that when evaluated match the characteristics of the UMCG-SEHOS program. As the program is characterized by much direct hands-on experience it is evident that the program is rich in fostering "participatory" competencies (next to the standard "acquired competencies") that are related to the social, cultural and contextual situation. This competency type is primarily based on participation and interaction with others. ${ }^{15}$ Resourceful learning with "desirable difficulties" is part of their daily 
Table 1. UMCG-SEHOS program and proposed Global Health learning outcomes (according to Johnson et al. $^{3}$ and Jogerst et al. ${ }^{6}$ )

\begin{tabular}{|c|c|}
\hline $\begin{array}{l}\text { Global Health } \\
\text { learning outcome }\end{array}$ & UMCG-SEHOS program feature \\
\hline $\begin{array}{l}\text { Global Burden of } \\
\text { Disease }\end{array}$ & $\begin{array}{l}\text { Infectious diseases: endemic area for emerging viruses like Zika and Chikungunya; related health care } \\
\text { challenges. Non-communicable diseases: high prevalence of diabetes, obesity, and hypertension. Impact of } \\
\text { high prevalence of end-stage renal disease. }\end{array}$ \\
\hline $\begin{array}{l}\text { Socioeconomic } \\
\text { and } \\
\text { environmental } \\
\text { determinants of } \\
\text { health }\end{array}$ & $\begin{array}{l}\text { Impact of local social and economic disparity on healthcare awareness and disease prevalence (in } \\
\text { comparison to the Netherlands). }\end{array}$ \\
\hline $\begin{array}{l}\text { Global Health } \\
\text { Governance }\end{array}$ & $\begin{array}{l}\text { Public Health rotation program for interns includes a weeklong orientation course on local healthcare } \\
\text { organization (including the role of PAHO/WHO). Participation during rotations in projects focusing on } \\
\text { effective infectious disease management within the Kingdom of the Netherlands. }\end{array}$ \\
\hline Health Systems & $\begin{array}{l}\text { Aging population with limited resources; cost effectiveness and required reliance on basic clinical skills and } \\
\text { principles and less on supporting techniques (e.g. radiology and laboratory determinations). Evaluation by } \\
\text { students of professional practice of individual medical specialists. }\end{array}$ \\
\hline $\begin{array}{l}\text { Human rights and } \\
\text { ethics }\end{array}$ & Vulnerable groups, immigrants and uninsured patients are daily treated \\
\hline $\begin{array}{l}\text { Cultural diversity } \\
\text { and health }\end{array}$ & Complete immersion of the intern in a non-Dutch society with clear effects of culture on patient behaviour. \\
\hline Communication & $\begin{array}{l}\text { Making effective use of the local native language in order to effectively communicate with patient and other } \\
\text { professionals on a daily basis. Patients with different ethnic, religious and social background. }\end{array}$ \\
\hline
\end{tabular}

PAHO - Pan American Health Organization; WHO - World Health Organization.

activities in a resource-limited setting. For these students, social justice and health equity are issues they encounter daily and more intensively in such a working environment when compared to the training environments in the Netherlands.

\section{UMCG-SEHOS PROGRAM AND CULTURAL COMPETENCE/CULTURAL AWARENESS}

The term "cultural competency or cultural awareness" has been proposed to describe an area of development for trainees participating in a GH education program. Although several authors have tried to define the term "culture" it is becoming clear that next to religion, language and education, the socio-economic class of the members of a community need to be added to the list of descriptors of "culture". Interestingly, the relevance of socio-economic class has grown significantly in many high-income countries as socio-economic status has clearly been linked to different health outcomes and individuals' perceptions of healthcare. ${ }^{15}$ Also, with the expanding migration of populations and the associated economic challenges, medical professionals increasingly need to understand the perspectives of new members migrating into their communities. The impact of health disparities and culture related communication skills have therefore become an essential part of the practice of medicine in high-income countries. ${ }^{4}$ By being completely immersed in a different culture the UMCG-SEHOS residents experience these challenges on a daily basis.

\section{GLOBAL HEALTH PROGRAMS, OUTCOMES AND CANADIAN MEDICAL EDUCATION DIRECTIVES FOR SPECIALISTS (CANMEDS) COMPETENCIES}

Measuring outcomes of GH education programs on both individual and structural level is still a challenge ${ }^{4}$ and there is a need to evaluate long-term outcomes and for future research in this area across a wide range of existing programs. ${ }^{6,16}$ Over the past 50 years, the collaboration between UMCG and SEHOS has not only impacted the educational aspirations of the UMCG but has also resulted in opportunities for successful scientific research by local professionals with high impact on local patient care. ${ }^{17-19}$

This collaboration has also contributed significantly to the continuous professional development of local health care providers in Curaçao ensuring maintenance of professional competencies of local medical staff through regular training programs and health care quality audits. Additionally an accredited monthly post-graduate educational program is provided to medical professionals by NASKHO (see www.NASKHO.org)

From a workforce development point of view, a number of tangible benefits have emerged from the longstanding collaboration between UMCG and SEHOS. The program has structurally provided a training platform for locals in their own community. As a result, upon graduation, several trainees (most of them natives of Curaçao) who underwent their global health rotation in Curacao returned to the island to join local healthcare workforce and contributed to a number of healthcare improvement initiatives both within and outside the hospital. Concrete examples of what the 
Table 2. Local areas of impact and achievements of the UMCG-SEHOS program

\begin{tabular}{|c|c|}
\hline $\begin{array}{l}\text { Local areas of } \\
\text { impact }\end{array}$ & Achievements \\
\hline $\begin{array}{l}\text { 1. The } \\
\text { educational } \\
\text { aspirations of } \\
\text { the UMCG and } \\
\text { SEHOS }\end{array}$ & $\begin{array}{l}\text { The UMCG elective program has resulted in an educational infrastructure that effectively caters for the } \\
\text { exposure of Dutch medical students to the practice of medicine in a resource limited environment. This resulted } \\
\text { in a concomitant need and opportunity to offer training electives in internal medicine, pediatrics, neurology, } \\
\text { general surgery and emergency medicine to Dutch and Belgian residents. }{ }^{22} \text { The opportunities for clinical and } \\
\text { educational scientific research among residents and local specialists have resulted in several PhD dissertations } \\
\text { and scientific publications. }{ }^{17-19} \text { These results have further strengthened the educational setting on the island } \\
\text { with several long term research and concomitant educational programs on (locally) relevant topics like clinical } \\
\text { leadership, HIV and emerging infectious diseases in collaboration with UMCG and other international } \\
\text { institutes. }\end{array}$ \\
\hline $\begin{array}{l}\text { 2. Continuous } \\
\text { professional } \\
\text { development } \\
\text { of local health } \\
\text { care providers }\end{array}$ & $\begin{array}{l}\text { One of the objectives of SEHOS is ensuring that the professional competencies of their staff is maintained in } \\
\text { their chosen domains of expertise. Participation in continuous professional development is therefore } \\
\text { mandatory. The continuous and steady influx of trainees to the hospital also helps sustain this process of } \\
\text { ongoing professional development in teaching faculty through the vibrant educational climate and the } \\
\text { stimulating academic discussions that emerge from the challenging questions the young and eager students } \\
\text { pose to the teaching faculty. Hence, local faculty (medical specialists) have had to be trained in the new and } \\
\text { current forms of educational practices, while keeping their knowledge of discipline up to date in a critical and } \\
\text { learning environment. This has resulted in the development of a specific curricular framework in SEHOS that } \\
\text { aligns with the educational objectives of the Dutch and UMCG medical curriculum. }{ }^{12,23} \text { Teacher training } \\
\text { programs designed in collaboration with the UMCG are provided annually to local medical professionals to } \\
\text { improve the quality of teaching and supervision of trainees. (e.g. Teaching on the run). }{ }^{24} \text { Furthermore a Dutch } \\
\text { accredited post-graduate educational program on varying medical topics is provided by the NASKHO on a } \\
\text { monthly basis (see www. NASKHO.org). }\end{array}$ \\
\hline $\begin{array}{l}3 . \\
\text { Transformation } \\
\text { of the local } \\
\text { health care } \\
\text { delivery } \\
\text { process, }\end{array}$ & $\begin{array}{l}\text { The collaborative efforts between the UMCG and SEHOS over the years have fostered extensive academic } \\
\text { networks between local and Dutch medical professionals. A couple of health care projects that have been } \\
\text { jointly initiated and realized include departmental quality improvement audits, staff support initiatives through } \\
\text { modern communication technologies (e.g. electronic patient rounds, video conferences) and improved patient } \\
\text { care through referral services to tertiary centers in the Netherlands (e.g. pediatrics with UMCG and Academic } \\
\text { Medical Center Amsterdam, hematology with Erasmus Medical Center, Rotterdam). This network has also } \\
\text { facilitated various continuous professional education initiatives }{ }^{24} \text {, which have been expanded to include } \\
\text { UMCG supported postgraduate training programs for nurses. }\end{array}$ \\
\hline $\begin{array}{l}\text { 4. Provision of } \\
\text { improved } \\
\text { health services } \\
\text { to the } \\
\text { inhabitants of } \\
\text { the island }\end{array}$ & $\begin{array}{l}\text { The presence of a residency program in Curaçao has had positive effects on the hospitals clinical infrastructure } \\
\text { (e.g. the opportunity to offer tertiary health care services to vulnerable and premature children in a NICU) as } \\
\text { well as, impetus for national healthcare reform in Curaçao (i.e. the development of a reference document for } \\
\text { the implementation of competency based health care delivery on the island) } 22 \text {. These developments align with } \\
\text { the aspirations of global health as well as the principles of transformational learning i.e. developing a } \\
\text { continuous learning organizational environment that can even serve as a structural basis for health care reform } \\
\text { in a resource limited setting. }{ }^{4,12}\end{array}$ \\
\hline
\end{tabular}

NICU - neonatal intensive care unit.

UMCG-SEHOS program added to the transformation of the local health care delivery process and how it improved health services to the inhabitants of the island are summarized in Table 2. These include the creation of networks and collaborative efforts for optimal patient care and the use of modern technologies to provide tertiary health care services to patients. ${ }^{20} \mathrm{~A}$ significant proportion of the medical specialists (46\%) currently working in SEHOS are products of the UMCG-SEHOS program for residents and interns (see Table 3, part A) and have played important roles in developing tertiary care departments (e.g. neonatal intensive care unit (NICU) for premature and severely ill newborns, hemato-oncology unit and a dialysis unit for the effective treatment of end-stage renal disease patients) in SEHOS thereby contributing to healthcare improvement efforts on the island (see Table 3, part B). Several initiatives for continuous quality improvement e.g. departmental audits and national healthcare reform initiatives have also been implemented as a result of the collaborative program. ${ }^{21}$

When specifically considering GH outcomes our group has published several reports on outcomes of the collabo- rative program between the UMCG and SEHOS (see Table 4). These studies have demonstrated the positive impact of the CANMEDS framework on the competencies of physicians who trained in Curaçao as well as on the organization of health care delivery within the community. ${ }^{12,23,25}$ Recent studies have also demonstrated how these interventions have contributed to identifying the causes and potential solutions for dilemmas within the health care process. ${ }^{26}$ These published results demonstrate the positive (longterm) outcome of GH programs at the organizational and individual levels. Furthermore, trainees in the GH program felt better prepared in their roles as health care managers. ${ }^{22}$

This topic remains an interesting area for future exploration in $\mathrm{GH}$ education and is equally valuable for other institutions that may want to develop new programs in $\mathrm{GH}$ education. 8

\section{EFFECTIVE PARTNERSHIP CHARACTERISTICS}

Realizing effective partnerships in GH education has been a challenge remaining mostly unbalanced in nature and pro- 
Table 3. Departments trained in UMCG-SEHOS program

\begin{tabular}{|c|c|c|c|c|}
\hline \multirow[t]{13}{*}{ A } & \multicolumn{4}{|c|}{ Overview of departments SEHOS with medical staff trained in UMCG-SEHOS program } \\
\hline & Department & $\begin{array}{l}\text { Total Medical } \\
\text { Staff }\end{array}$ & $\begin{array}{l}\text { Participated } \\
\text { in local } \\
\text { program }\end{array}$ & Cumulative Percentage of locally trained doctors on staff \\
\hline & $\begin{array}{l}\text { Internal } \\
\text { Medicine }\end{array}$ & 11 & $7(63 \%)$ & 11.6 \\
\hline & Surgery & 8 & $4(50 \%)$ & 6.6 \\
\hline & Neurology & 5 & $1(20 \%)$ & 1.6 \\
\hline & Pediatrics & 7 & $2(28.5 \%)$ & 3.3 \\
\hline & $\begin{array}{l}\text { Obstetrics \& } \\
\text { Gynaecology }\end{array}$ & 8 & $4(50 \%)$ & 6.6 \\
\hline & Cardiology & 8 & $3(37.5 \%)$ & 5 \\
\hline & Pulmonology & 3 & $1(33.3 \%)$ & 1.6 \\
\hline & Anasthesiology & 6 & $3(50 \%)$ & 5 \\
\hline & Radiotherapy & 2 & $2(100 \%)$ & 3.3 \\
\hline & Dermatology & 2 & $1(50 \%)$ & 1.6 \\
\hline & TOTAL & 60 & 28 & 46.2 \\
\hline \multirow[t]{5}{*}{ B } & \multicolumn{4}{|c|}{ High complexity departments SEHOS that have emerged through products of the UMCG-SEHOS collaboration } \\
\hline & Department & Personnel & $\begin{array}{l}\text { Locally } \\
\text { trained } \\
\text { medical } \\
\text { specialists }\end{array}$ & Characteristics \\
\hline & $\begin{array}{l}\text { Hemato- } \\
\text { Oncology }\end{array}$ & $\begin{array}{l}3 \text { Hemato- } \\
\text { oncologists } 4 \\
\text { Oncology nurses } \\
\text { (daycare) }\end{array}$ & 1 & $\begin{array}{l}\text { Daycare: } 9 \text { chairs and } 4 \text { beds } 3000 \text { treatments/year } \\
\text { Medical ward: } 16 \text { beds Turnover: } 500 \text { patients/year }\end{array}$ \\
\hline & Radiotherapy & $\begin{array}{l}2 \text { Clinical } \\
\text { oncologists } 8 \\
\text { radiotherapy } \\
\text { technicians }\end{array}$ & 2 & 1 Linear Accelerator Turnover: 500 patients/year \\
\hline & $\begin{array}{l}\text { Nephrology- } \\
\text { Dialysis }\end{array}$ & $\begin{array}{l}4 \text { Nephrologists } \\
21 \text { Dialysis } \\
\text { nurses }\end{array}$ & 3 & $\begin{array}{l}250 \text { patients on Hemodialysis } 60 \text { patients on Continuous } \\
\text { Ambulatory peritoneal dialysis Active kidney transplant } \\
\text { program with }>100 \text { patients treated }\end{array}$ \\
\hline
\end{tabular}

viding insufficient value/benefit for the host institute/country. ${ }^{27,28}$ As described well-designed and structured medical education programs can be a sound basis for successful collaboration $^{28}$, as judged by the quality of the experience of the trainees, improvement of in-country care, infrastructure and health capacity expansion. ${ }^{7,9}$ A comparison of the characteristics of the UMCG-SEHOS program with the proposed critical components for a successful collaboration ${ }^{28}$ is presented in Table 5.

\section{CONCLUSIONS}

Regarding health (in)equity, the concepts of systematic differences and their associated health risks as experienced by disadvantaged groups (social, racial, ethnic, economic or demographic) are consistently becoming an issue of importance, as these conditions also increasingly exist in western countries. ${ }^{29}$

The increasingly globalized healthcare requires educational programs to adapt in order to meet these expectations. Hence the addition of GH competencies to the formal medical programs and the need for measurement of these educational outcomes for doctors to achieve better and effective patient management. ${ }^{29}$

As argued by Frenk et al. ${ }^{4}$, it is essential that the focus be on the transformative learning aspects encountered in addition to the reflective learning that occurs. The use of cross-cultural effective ideas stemming from diverse societies can also lead to better strategic analyses and effective approaches for patient treatment and prevention of disease $^{30}$, ultimately resulting in the necessary "change agents" in healthcare. ${ }^{4}$

To our knowledge this is one of the first innovative initiatives in medical education where an official clinical clerkship curriculum has been successfully run as a standalone program in a different cultural and social learning setting. This project serves to show viability of GH programs when the priorities, needs and preferences of the various partners are aligned with each other i.e. the educational goals and targeted improvements in the quality of care. ${ }^{29}$ It is also an excellent example of bidirectional collaboration and sharing of information and ideas between educational institutions in western and non-western settings (local input for the program include shared public health programs and re- 
Table 4. Published outcomes UMCG-SEHOS collaborative program on medical education

\begin{tabular}{|l|l|c|}
\hline GH objective & Outcome & Reference \\
\hline $\begin{array}{l}\text { Improved health care system } \\
\text { organization }\end{array}$ & $\begin{array}{l}\text { Importance of quality of education process maintenance; collaborative } \\
\text { efforts with international medical institutes crucial }\end{array}$ & 25 \\
\hline $\begin{array}{l}\text { Competency and preparedness } \\
\text { for clinical practice }\end{array}$ & Caribbean culture trainees felt better prepared as health care manager & 22 \\
\hline $\begin{array}{l}\text { Introduction of competencies } \\
\text { based curriculum }\end{array}$ & $\begin{array}{l}\text { Successful implementation in a resource limited environment. Crucial } \\
\text { importance of local educational experts }\end{array}$ & 23 \\
\hline $\begin{array}{l}\text { Improvement of competency } \\
\text { based curriculum in the } \\
\text { Caribbean }\end{array}$ & $\begin{array}{l}\text { Importance of improvement of interprofessional communication and } \\
\text { structure of clinical rotation }\end{array}$ & 12 \\
\hline $\begin{array}{l}\text { Critical assessment of health } \\
\text { practices }\end{array}$ & $\begin{array}{l}\text { Mixed method focus group sessions to effectively determine communication } \\
\text { and key improvement areas in a small-scale limited resources setting }\end{array}$ & 26 \\
\hline
\end{tabular}

Table 5. UMCG-SEHOS program and selection of core components of equitable global health education and practice for successful partnerships according to Adams et $\mathrm{al}^{28}$

\begin{tabular}{|l|l|}
\hline Core component & UMCG-SEHOS program \\
\hline $\begin{array}{l}\text { Engaging } \\
\text { interdisciplinary teams }\end{array}$ & $\begin{array}{l}\text { Infrastructure and functionalities of an official affiliated teaching hospital requiring effective } \\
\text { collaboration between hospitals and respective departments }\end{array}$ \\
\hline Equitable partnerships & Infrastructure and functionalities of an official affiliated teaching hospital \\
\hline Priorities alignment & Effective internship program and health care quality improvement as a teaching hospital \\
\hline $\begin{array}{l}\text { Transparent program } \\
\text { management }\end{array}$ & $\begin{array}{l}\text { Creation of NASKHO as an administrative vehicle tasked with the organization and coordination of } \\
\text { the collaborative training program }\end{array}$ \\
\hline Education of trainees & Native Curaçao interns prioritized for participating in program \\
\hline $\begin{array}{l}\text { Applications for funding } \\
\text { jointly conceived and } \\
\text { written }\end{array}$ & $\begin{array}{l}\text { Research grant applications for PhD programs on relevant topics like HIV, clinical leadership and } \\
\text { emerging infectious diseases (e.g. Netherlands Organisation for Scientific Research (NWO) grants) }\end{array}$ \\
\hline $\begin{array}{l}\text { Research conducted } \\
\text { jointly with shared roles }\end{array}$ & Several successful long-running research/PhD programs jointly conducted ${ }^{17-19}$ \\
\hline
\end{tabular}

search projects, introduction of community tasks during clerkship, and the treatment of diseases like sickle cell disease, end-stage renal disease and HIV). ${ }^{5}$ It is important to note that most of the local teaching faculty in SEHOS are Dutch trained and are therefore familiar with the medical educational curriculum in Netherlands, which was of added value to the long term sustenance of the program.

In conclusion, we believe that our results to date contribute tangibly to the ongoing discourse on GH education worldwide. It helps in broadening the perspective and conceptualization of GH education and presents new areas for collaboration and mutual benefit for partnering institutions and countries. ${ }^{5}$ As an GH intervention, it contributes to the reform of health professions education, emphasizing patient and population centeredness and professional leadership skills.
Funding: None.

Authorship contributions: AJD, JBK and JOB conceived and performed the analysis and wrote the manuscript.

Competing interests: The authors have completed the Unified Competing Interest form at www.icmje.org/coi disclosure.pdf (available upon request from the corresponding author) and declare no conflicts of interest.

\section{Correspondence to:}

Ashley J. Duits

Professor of Medical Education

Red Cross Blood Bank Foundation Curaçao

Pater Euwensweg z/n

Willemstad, Curaçao

ajduits@gmail.com 


\section{REFERENCES}

1. Gabriel M, Emmerich P, Frank C, et al. Increase in West Nile virus infections imported to Germany in 2012. Journal of Clinical Virology.

2013;58(3):587-589. doi:10.1016/j.jcv.2013.08.027

2. Oligbu G. Rare and imported infections: Are we prepared? Pharmacy. 2019;7(1):9. doi:10.3390/pharm acy7010009

3. Johnson O, Bailey SL, Willott C, et al. Global health learning outcomes for medical students in the UK. The Lancet. 2012;379(9831):2033-2035. doi:10.1016/s 0140-6736(11)61582-1

4. Frenk J, Chen L, Bhutta ZA, et al. Health professionals for a new century: Transforming education to strengthen health systems in an interdependent world. The Lancet. 2010;376(9756):1923-1958. doi:10.1016/s0140-6736(1 0)61854-5

5. Peluso MJ, van Schalkwyk S, Kellett A, et al. Reframing undergraduate medical education in global health: Rationale and key principles from the Bellagio Global Health Education Initiative. Medical Teacher. 2017;39(6):639-645. doi:10.1080/0142159x.2017.1301 654

6. Jogerst K, Callender B, Adams V, et al. Identifying Interprofessional Global Health Competencies for 21st-Century Health Professionals. Annals of Global Health. 2015;81(2):239. doi:10.1016/j.aogh.2015.03.0 $\underline{06}$

7. Kerry VB, Ndung'u T, Walensky RP, Lee PT, Kayanja VFIB, Bangsberg DR. Managing the demand for global health education. PLoS Med. 2011;8(11):e1001118. do i:10.1371/journal.pmed.1001118

8. Battat R, Seidman G, Chadi N, et al. Global health competencies and approaches in medical education: A literature review. BMC Med Educ. 2010;10(1). doi:1 0.1186/1472-6920-10-94

9. Koster MP, Williams JH, Gautier J, Alce R, Trappey BE. Front Public Health. 2017;30:122.

10. Pfeiffer J, Beschta J, Hohl S, Gloyd S, Hagopian A, Wasserheit J. Competency-based curricula to transform global health: Redesign with the end in mind. Academic Medicine. 2013;88(1):131-136. doi:1 0.1097/acm.0b013e318276bdf4
11. Myers KR, Fredrick NB. Team investment and longitudinal relationships: An innovative global health education model. Academic Medicine. 2017;92(12):1700-1703. doi:10.1097/acm.0000000000 $\underline{001768}$

12. Busari JO, Duits AJ. The strategic role of competency based medical education in health care reform: A case report from a small scale, resource limited, Caribbean setting. BMC Research Notes. 2015;8(1):13-21. doi:10.1186/s13104-014-0963-1

13. Dutch Blueprint: Raamplan Artsenopleiding 2009. Nederlandse Federatie van Universitaire Medische Centra. Utrecht: Dutch Federation of University Medical Centers; 2009.

14. Kuks JBM. The bachelor-master structure (twocycle curriculum) according to the Bologna agreement: A Dutch experience. GMS Zeitschrift für Medizinische Ausbildung. 2010;27:ISSN 1860-3572.

15. Eichbaum Q. Acquired and participatory competencies in health professions education: Definition and assessment in global health. Academic Medicine. 2017;92(4):468-474. doi:10.1097/acm.0000 000000001382

16. Crump JA, Sugarman J. the Working Group on Ethics Guidelines for Global Health Training (WEIGHT). Global health training ethics and best practice guidelines for training experiences in global health. Am J Trop Med Hyg. 2010;83:1178-1182. doi:1 0.4269/ajtmh.2010.10-0527

17. Hermanides HS, van Vught LA, Voigt R, et al. Developing quality indicators for the care of HIVinfected pregnant women in the Dutch Caribbean. AIDS Res Ther. 2011;8(1):32. doi:10.1186/1742-640 $\underline{5-8-32}$

18. Hermanides HS, Holman R, Gras L, et al. High incidence of intermittent care in HIV-1-infected patients in Curaçao before and after starting cART. AIDS Care. 2013;25(11):1411-1417. doi:10.1080/0954 $\underline{0121.2013 .772276}$

19. Landburg PP, Teerlink T, Biemond BJ, et al. Plasma asymmetric dimethylarginine concentrations in sickle cell disease are related to the hemolytic phenotype. Blood Cells, Molecules, and Diseases. 2010;44(4):229-232. doi:10.1016/j.bcmd.2010.02.005 
20. Minnee RC, Lardy N, Ajubi N, et al. Ten-yr results of the trans-atlantic kidney transplant airlift between the Dutch Caribbean and the Netherlands. Clinical Transplantation. 2011;25(2):302-307. doi:10.1111/j.13 99-0012.2010.01239.x

21. Busari JO, Duits AJ. Quality Requirements of Competency-Based Medical Care in Curaçao.; 2012.

22. Busari JO, Verhagen EA, Muskiet FD. The influence of the cultural climate of the training environment on physicians' self-perception of competence and preparedness for practice. BMC Med Educ. 2008;8(1):51-58. doi:10.1186/1472-6920-8-51

23. Koeijers J, Busari JO, Duits AJ. A case study of the implementation of a competency-based curriculum in a Caribbean teaching hospital. West Indian Med J. 2012;61:726-732.

24. Lefroy J, Watling C, Teunissen PW, Brand P. Guidelines: The do's, don'ts and don't knows of feedback for clinical education. Perspect Med Educ. 2015;4(6):284-299. doi:10.1007/s40037-015-0231-7

25. Busari JO, Verhagen EAA, Muskiet FD, Duits AJ. Implementation of a competency-based residency curriculum: Experiences from a resource-limited environment in the Caribbean. Medical Teacher. 2008;30(9-10):e189-e195. doi:10.1080/014215908023 37112
26. Busari JO, Moll FM, Duits AJ. Understanding the impact of interprofessional collaboration on the quality of care: A case report from a small-scale resource limited health care environment. JMDH. 2017; Volume 10:227-234. doi:10.2147/jmdh.s140042

27. Crane J. Scrambling for Africa? Universities and global health. Lancet. 2011;337:1388-1390. doi:10.10 16/S0140-6736(10)61920-4

28. Adams LV, Wagner CM, Nutt CT, Binagwaho A. The future of global health education: Training for equity in global health. BMC Med Educ. 2016;16(1):296-303. doi:10.1186/s12909-016-0820-0

29. Wass V, Mole TB. Contextually balanced medical education: Realigning with global health care delivery. Med Educ. 2017;51(8):773-775. doi:10.1111/ medu. 13360

30. Koplan JP, Bond TC, Merson MH, et al. Towards a common definition of global health. The Lancet. 2009;373(9679):1993-1995. doi:10.1016/s0140-6736(0 9)60332-9 